\title{
THE EFFECTIVENESS OF THE ORIENTATION PROGRAMME ON NEWLY RECRUITED BASIC BSC STAFF NURSES AT KRISHNA HOSPITAL, KARAD
}

\author{
Rohini Babar1, Kavita S. Kapurkar², Sandhya Jagadale3, K. S. Jadhav 4, M. P. Jagtap 5 , S. J. Talbar 6
}

${ }^{1}$ Nursing Superintendent, Krishna Institute of Nursing Sciences, Karad, Satara.

${ }^{2}$ Nurse Educator, Krishna Institute of Nursing Sciences, Karad, Satara.

${ }^{3}$ Nurse Educator, Krishna Institute of Nursing Sciences, Karad, Satara.

${ }^{4}$ Nursing Supervisor, Krishna Institute of Nursing Sciences, Karad.

${ }_{5}^{5}$ ursing Supervisor, Krishna Institute of Nursing Sciences, Karad.

${ }^{6}$ Nursing Supervisor, Krishna Institute of Nursing Sciences, Karad.

\section{ABSTRACT}

\section{BACKGROUND}

The development of formal orientation programs in health is critical in the recruitment and retention of nursing staff. The importance of effective programs is especially so for graduate nurses beginning their career. Literature demonstrates that a comprehensive, well thought out programme can reduce adjustment periods for novice nurses, minimise turnover and establish a solid foundation for a productive and lengthy career. ${ }^{1}$ The study was conducted on 32 newly recruited staff nurses at Krishna Hospital, Karad.

Aims of this study "to assess the effectiveness of planned teaching programme on orientation regarding responsibility of staff nurses among newly appointed Basic B.Sc nurses at Krishna Hospital, Karad" are,

1. To assess the knowledge and practice regarding responsibilities of staff nurses before and after orientation programme.

2. To find an effectiveness of Planned Teaching Programme on orientation.

3. To find an association of knowledge and practice between pre-test and post-test of PTP on orientation.

4. To find an association of pre-test knowledge and practice with demographic variable.

\section{RESULTS}

The study was conducted on 32 newly recruited staff nurses at Krishna Hospital, Karad. An Evaluatory survey approach was considered. Study design used was one group pre-test/post-test design. Purposive sampling technique method was used.

\section{CONCLUSION}

Study concludes in pre-test newly recruited nursing staff having majority of $50 \%$ average knowledge and $50 \%$ good practice and in post-test newly recruited nursing staff having majority of $65.62 \%$ good knowledge and majority of $81.25 \%$ having good practice. It reveals that planned orientation teaching programme regarding responsibility of staff nurses is effective. Knowledge and practice score of newly recruited nursing staff between the pre-test and post-test was highly significant.

\section{KEYWORDS}

Knowledge, Practice, Orientation Programme, Staff Nurses. PTP.

HOW TO CITE THIS ARTICLE: Babar R, Kapurkar KS, Jagadale S, et al. The effectiveness of the orientation programme on newly recruited Basic B.Sc staff nurses at Krishna Hospital, Karad. J. Evolution Med. Dent. Sci. 2016;5(91):6777-6782, D0I: 10.14260/jemds/2016/1531

\section{BACKGROUND}

Nursing orientation programs provide new employees with the opportunity to become familiar with the organisation's structure, culture, and standards. During this time, new hires can gain an understanding about what is expected of them by the organisation and what they should expect from the organisation. ${ }^{2}$

Program updates should include evidence-based practice changes, informatics upgrades, and new or modified policies and procedures. Successful nursing orientation programs

Financial or Other, Competing Interest: None.

Submission 08-10-2016, Peer Review 02-11-2016,

Acceptance 07-11-2016, Published 14-11-2016.

Corresponding Author:

Rohini Babar,

Krishna Hospital \& Medical Research Centre,

Karad, Satara,

Maharashtra.

E-mail: rohinivbabar@gmail.com

DOI: $10.14260 /$ jemds/2016/1531 need to be comprehensive, engage adult learners, and encourage sharing and integration of information. ${ }^{2}$

A successful nursing orientation programme must take into account the organisation, the nurses, and the needs of the nurses. The orientation programme should be integrated into the overall organisational strategy. One of the primary reasons for nursing orientation is to ensure that new employees understand and retain the policies and procedures for patient safety. The orientation period is an ideal opportunity to present the organisation's safe practices. ${ }^{3}$ It is vital for an organisation to have a formal orientation programme in order to retain and motivate employees, decrease turnover, increase productivity, improve staff morale, facilitate learning, and reduce anxiety of new employees. By the year 2025, it is anticipated that the nursing shortage will reach 500,000 registered nurses. ${ }^{3}$ Therefore, it is the responsibility of organisations to enhance their orientation programs to increase nurse retention and track outcomes for the costeffectiveness of these programs. Orientation programs need to be continuously updated as a result of constant changes in health care. ${ }^{3}$ 
Gaps in an orientation programme indicate a need for a better understanding of the requirements of the adult learner and the high cost of replacing newly hired nurses. ${ }^{3}$ The development of formal orientation programs in health is critical in the recruitment and retention of nursing staff. The importance of effective programs is especially so for graduate nurses beginning their career. Literature demonstrates that a comprehensive, well thought out programme can reduce adjustment periods for novice nurses, minimise turnover and establish a solid foundation for a productive and lengthy career. ${ }^{4}$

Definition to 'orientate' is to adjust to new circumstances, surroundings and or facts. Anecdotally the term orientation used in the nursing context, refers to a course introducing a new situation or environment. 4

The main reasons for orientation are to enhance skills and knowledge in the new graduate, to facilitate the integration of Theory and practice and to ease the new graduates' transition from university life to the clinical setting. ${ }^{2}$ Structural empowerment, better working conditions (Manageable workloads, control over work, rewarding, fairness, a sense of belonging, congruence between personal and organisational values) and authentic leadership are significantly related to job and career satisfaction and turnover intentions among new nurses. The new graduates felt that their initial orientation met their needs and they were satisfied with their career and less likely to leave the nursing profession. ${ }^{4}$

Orientation programs add to novice nurses' ability to perform prescribed duties, increases confidence, competence and job satisfaction of graduate nurses, but also collegiality among experienced and novice nurses. It lowers the turnover rates, reduces turnover costs and enhances the quality of nursing care by, for example, decreasing medication errors. According to Lee et al, the orientation programme decreased the turnover rates of new nurses by almost $47 \%$, which decreased turnover costs by $\$ 186,102$. A systematic orientation programme also enhances organisations' good employer reputation and attracts new employees. ${ }^{5}$

\section{Background to the Study}

Anecdotal evidence alludes to the poor performance of health professionals due to inadequate induction and orientation programmes as well as a lack of non-career development and support. Newly recruited health care professionals, in various positions, namely, professionals who have recently completed their studies, long serving health professionals in new health facilities and those in promotional posts, find it difficult to settle in to their new positions. The inability to settle in results in low productivity at the health facilities.

\section{Most health employees who left the Health Department} indicated that they did so due to

1. Lack of effective induction programmes.

2. Low morale of long serving and new recruits in the Health Department.

3. Poor communication which results in poor integration into team work

4. No feedback mechanism for inducted employees.

5. No clear outline of the role requirement for new employees.
A common induction programme for all health professionals is being implemented, which means a "one size fits all" approach. This process is unlikely to satisfy the needs of all health professionals. ${ }^{2}$

\section{Orientation Programme}

"Bridging the Gap" is aim of classroom programme and clinical learning progress using simple to complex theory and skill competencies.

- Staff qualifications are defined specific to job responsibilities.

- Verification of staff qualifications.

- Orientation is provided to staff.

- Key safety content is provided to staff prior to staff providing care, treatment, or services.

- $\quad$ Staff is oriented to organisational specific policies and procedures; specific job duties, including those related to infection prevention and control as well as assessing and managing pain; sensitivity to cultural diversity; patient rights and ethical aspects of care; waived testing. ${ }^{4}$

- Role transition.

- Giving/receiving end-of-shift report.

- Case studies in fluid \& electrolyte imbalances/lab interpretation.

- IV/phlebotomy practicum.

- Blood product review.

- Restraint/fall protocols.

- Skin/wound/ostomy issues.

- Pain management.

- $\quad$ DNR and post-mortem care.

- Oxygen delivery systems.

- Chest tube drainage systems.

- Central lines.

- Organ and tissue donation.

- Critical thinking.

- Mock code programme Highlights.

\section{Programme Highlights}

- Customised 1 week "Bridging the Gap" Orientation Programme.

- Integrated Class and Clinical Training.

- Dedicated Preceptors are pulled from the staff pattern to give you focused attention.

- Tertiary Hospital Setting-Avoid Getting Lost in the Crowd.

- Variety of Nursing Specialties and Shift Options. ${ }^{5}$

\section{Need for Study}

The benefits of orientation are clear and visible to both the new employee and the organisation, says Jean Barbazette of The Training Clinic. The organisation benefits from such factors as reduced turnover or improved productivity as a few of the benefits of a systematic orientation. Employees benefit from feeling valued and "fitting in" to the new job more easily and quickly. And, she says, fewer mistakes are made by the new employees who are more relaxed. ${ }^{6}$

The greatest benefit to effective orientation, says Lin Grensing-Pophal, author of "Human Resource Essentials", is the ability for the organisation to acclimate the new employee to the culture of the organisation. Many cultural norms are 
subtle and unstated. Employee orientation can offer an opportunity for new employees to meet and interact with role models who can serve as coaches and mentors during the orientation process. ${ }^{6}$

The goal of an orientation programme is to prepare new Staff nurses to be confident and to provide competent and safe patient care. Structured Orientation programmes facilitate newly graduated nurse Transition from novice to advanced beginner. The outcome of these programs is two-fold: First, they promote the confidence and competency level of new nurses in providing patient care, and second, they increase nurse retention. Furthermore, a high turnover and an influx of new graduates have led to a higher proportion of inexperienced nurses in direct patient care, which may not only be traumatic for the new professional nurse, but may also threaten patient safety. Therefore, for patient safety and the well-being of new nurses, hospitals must make efforts to provide safe and effective environments that foster the integration of graduate nurses into their systems. An effective orientation programme is one strategy that may address these concerns. ${ }^{7}$

Effective orientation either site or specialty specific objectives may exist during an orientation period, there are a number of recurrent themes through the literature identified as essential components. These include formal processes for adequate graduate support, some form of educational offerings and consideration of the adjustment required by the graduate; especially in terms of time taken to complete tasks, workload allocation and patient care. ${ }^{7}$

\section{Review of Literature}

Casey et al (2004) conducted a descriptive, comparative study utilising questionnaires to examine graduate nurse experiences during timed data periods in their year of transition into practice. A convenience sample of 270 new graduate nurses from six acute care organisations participated in the study and completed the Casey-Fink Graduate Nurse Experience Survey. The results indicated that new graduate nurses appreciated a longer orientation period (6-24 weeks depending on facility). Preceptor shield, a significant role in the new graduate's job satisfaction, provided an example of professional behaviour, and assisted nurses in adjusting to their new practice roles. The limitations of this study included a low response rate $(34 \%)$ by the end of the first year which could have affected the validity of the results. ${ }^{8}$

In a qualitative study by Charleston, Hayman-White, Ryan, and Happell (2007), responses from interviews were used to examine psychiatric graduate nurse programme (PGNP) and orientation practices. Purposeful selection yielded participants from 21 areas of mental health services. Participants included graduate nurses, nurse managers, nurse educators, staff nurses, consumer consultants, mental health nurse academics, and nursing students. Based on the findings, the majority of mental health services had an introductory orientation period that included formal education for mental health nursing, mandatory occupational health and safety sessions, and an overview of the organisation structure. The orientation periods ranged from 3 days to 2 weeks. According to Charleston et al (2007), "a number of participants" (p. 27) reported that the orientation period was not long enough for graduate nurse adjustment while others felt it was too long impeding integration with the organisation. Additionally, results indicated that the orientation period was not adequately structured which led to confusion regarding the new hire's role. Also, individual support, including preceptors and supervisors, were identified as important to the nurse's confidence level (Charleston et al 2007). The article did not identify the number of participants in the study and findings were not discussed based on the responses of the different health care positions represented in the sample (Nurses, nurse managers, educators, consultants, students, etc). ${ }^{9}$

Ward (2009) conducted a study on an acute care surgical unit of a community hospital and identified the need for a unitspecific orientation class in addition to the hospital's general orientation program. The purpose of the class was to better prepare new nursing staff for practice on the unit, increase job satisfaction, and increase retention on the unit. Twenty two new employees, including new and experienced nurses, completed the 2-day class. As a result of modifying the orientation class, the unit's 1-year nurse retention rate improved from $44 \%$ to $84 \%$. The nurses indicated that the unit class facilitated their identification with the established work group and increased their comfort level as they gained information on what was expected of them. A limitation of the study is that the type of pre-test post-test evaluation questionnaire was not identified. Additionally, liability and validity of the questionnaire was not discussed (Ward, 2009). 10

In another study, Bashford, Shaffer, and Young (2012) examined the value of competency-based assessments for newly hired RNs during their first phase of orientation. Data were collected via investigator-recorded field notes and survey responses of newly hired RNs. The surveys were mailed to the sample via interdepartmental mail 3 months after the competency-based assessment and consisted of several questions with a Likert scale and an available space for comments. The sample of $31 \mathrm{RNs}$ had a range of experience from 0-24 years. Results of the study supported use of a competency-based assessment as the nurses valued the enrichment of self-esteem, self-awareness of knowledge, and learning needs. The assessment validated the competence of newly hired nurses, which subsequently contributed to a practice environment that promotes patient safety and quality care. ${ }^{11}$

Kovner et al 2007 reported the high turnover of newly graduated nurses is emerging as one of the problems that hospitals need to address. In a current survey of newly graduated nurses in 35 states, approximately $13 \%$ of responders had changed principal jobs after 1 year, and $37 \%$ reported that they planned to change jobs in the near future. ${ }^{12}$

\section{Objective}

1. To assess the knowledge and practice regarding responsibilities of staff nurse before and after orientation programme.

2. To find an effectiveness of PTP on orientation.

3. To find an association of knowledge and practice between pre-test and post-test of PTP on orientation.

4. To find an association of pre-test knowledge and practice with demographic variable. 


\section{Operational Definition}

Orientation Programme- It is a period of time at the beginning of the tertiary institution which a variety of events are held to orient and welcome new staff.

\section{Effectiveness}

Effectiveness means outcome of the orientation programme.

\section{Delimitation}

The study will be limited to newly appointed Basic B.Sc nurses at Krishna Hospital, Karad.

\section{Hypothesis}

The hypothesis will be tested at 0.05 level of significance.

\section{$\mathrm{H}_{1}$}

There will be significant difference in the effectiveness of PTP among newly recruited staff nurses at Krishna Hospital, Karad.

\section{MATERIALS AND METHODS}

\section{Study Approach}

Evaluatory survey approach.

\section{Research Design}

The research design for the study was one group pretest/post-test.

\section{Setting}

The study was conducted in Krishna Hospital, Karad.

\section{Method of Data Collection}

Sampling Procedure

Samples will be selected by purposive sampling technique.

\section{Sample Size}

Total sample size for study: 32 newly appointed Basic B.Sc nurses.

\section{Inclusion Criteria}

a) Newly appointed Basic B.Sc nurses and willing to participate in study.

b) Those that are present during data collection.

\section{Exclusion Criteria for Sampling}

Those who are not willing to participate in the study.

\section{Instrument Used}

1. Demographic Proforma to find out the baseline variable.

2. Structured questionnaire.

\section{Data Collection Method}

The data will be collected using structured questionnaire.

\section{Data Analysis Plan}

Data analysis will be done using descriptive and inferential statistical methods to meet the objective of the study. Statistics such as frequency percentage, chi square and t-test will be used. Findings will be presented in form of tables and figures.

\section{Material Method}

The study was conducted on 32 newly recruited staff nurses at Krishna Hospital, Karad. An evaluatory survey approach was considered. Study design used was one group pre-test/posttest design. Purposive sampling technique was used. The instrument used for data collection was a Questionnaire of knowledge and practice.

\section{RESULTS}

\begin{tabular}{|c|c|c|c|}
\hline Sl. No. & Variables & Frequency & Percentage \% \\
\hline 1 & Age & & $37.5 \%$ \\
\hline & 21 yrs. & 12 & $62.5 \%$ \\
\hline & 22 yrs. & 20 & $81.25 \%$ \\
\hline 2 & Sex & & $18.75 \%$ \\
\hline & Female & 26 & $3.12 \%$ \\
\hline & Male & 6 & $65.63 \%$ \\
\hline 3 & Marks & & $31.25 \%$ \\
\hline & $>70 \%$ & 1 & 10 \\
\hline & $>60 \%$ & 21 & \\
\hline & $<50 \%$ & Distribution of newly Recruited Staff Nurses \\
\hline Table 1. Ding to Frequency and Percentage \\
of Demographic Variable. N=32
\end{tabular}

The data presented in table no. 1 reveals that majority (62.5\%) of newly recruited nursing staff belong to age group of 22 years. Maximum staff $(81.25 \%)$ were female, majority $(65.63 \%)$ staff were having $>60 \%$ marks.

\begin{tabular}{|c|c|c|}
\hline Categorisation & Knowledge (\%) & Practice (\%) \\
\hline Good & $7(21.87 \%)$ & $16(50 \%)$ \\
\hline Average & $16(50 \%)$ & $15(46.87 \%)$ \\
\hline Poor & $9(28.12 \%)$ & $1(3.12 \%)$ \\
\hline \multicolumn{2}{|c|}{ Table 2. Categorisation According to Pre-test } \\
Knowledge and Practice Score of \\
newly Recruited Nursing Staff. N=32
\end{tabular}

Table 2 Indicates that in pre-test, newly recruited nursing staff having majority of $50 \%$ average knowledge and $50 \%$ good practice of planned orientation teaching programme regarding responsibility of staff nurses.

\begin{tabular}{|c|c|c|}
\hline Categorisation & Knowledge \% & Practice \% \\
\hline Good & $21(65.62 \%)$ & $26(81.25 \%)$ \\
\hline Average & $11(34.37 \%)$ & $6(18.75 \%)$ \\
\hline Poor & 0 & 0 \\
\hline Table 3. Categorisation According to Post-test \\
Knowledge and Practice Score of \\
newly Recruited Nursing Staff. $\mathbf{N}=\mathbf{3 2}$ \\
\hline
\end{tabular}

Table 3 indicates that in post-test, newly recruited nursing staff having majority of $65.62 \%$ good knowledge and majority of $81.25 \%$ having good practice of planned orientation teaching programme regarding responsibility of staff nurses

\begin{tabular}{|c|c|c|c|c|c|}
\hline & Mean & SD & t value & Df & P.Value \\
\hline Pre-test & 31.9 & 6.9 & \multirow{2}{*}{5.633} & 310 Freedom & $<0.0001$ \\
\hline Post-test & 38.4 & 4.2 & & & \\
\hline \multicolumn{7}{|c|}{ Table 4. Pre-test and Post-test Knowledge and } \\
Practice Score of newly Recruited Nursing Staff. $\mathbf{N}=32$ \\
\hline
\end{tabular}


Table 4 reveals that there was significant difference between pre-test and post-test knowledge and practice of newly recruited staff nurses towards orientation programme $t=5.633$ with $31^{\circ}$ of freedom, $p$ value is $<0.0001$.

\begin{tabular}{|c|c|c|c|c|c|}
\hline Knowledge & Mean & SD & t value & Df & P Value \\
\hline Pre-test & 12.6 & 3.7 & \multirow{2}{*}{5.7163} & $\begin{array}{c}310 \\
\text { Freedom }\end{array}$ & $<0.0001$ \\
\hline Post-test & 16.9 & 3.7 & & \multicolumn{5}{|c|}{ Table 5. Knowledge Score of Pre-test and } \\
\hline \multicolumn{6}{|c|}{ Post-test of newly Recruited Nursing Staff. $\mathbf{N}=32$} \\
\hline
\end{tabular}

Table 5 shows that knowledge score of newly recruited nursing staff between the pre-test and post-test was highly significant as the $\mathrm{P}$ value is $<0.0001$.

\begin{tabular}{|c|c|c|c|c|c|}
\hline Practice & Mean & SD & $\begin{array}{c}\text { t } \\
\text { value }\end{array}$ & Df & $\begin{array}{c}\text { P } \\
\text { Value }\end{array}$ \\
\hline Pre test & 19.28 & 4.1 & 3.072 & $\begin{array}{c}310 \\
\text { freedom }\end{array}$ & 0.0044 \\
\hline Post-test & 21.4 & 1.7 & \multicolumn{5}{|c|}{ Table 6. Practice Score of Pre-test and Post-test } \\
of newly Recruited Nursing Staff. N=32 \\
\hline
\end{tabular}

Table 6 shows that practice score of newly recruited nursing staff between the pre-test and post-test was highly significant as the $\mathrm{P}$ value is $<0.0044$.

\begin{tabular}{|c|c|c|c|c|c|c|}
\hline Demographic & Good & Average & Poor & $\begin{array}{c}\text { Chi- } \\
\text { Square }\end{array}$ & Df & \begin{tabular}{|c|}
$P$ \\
value
\end{tabular} \\
\hline \multicolumn{7}{|l|}{ Age } \\
\hline 21 Yrs. & 4 & 6 & 2 & \multirow{3}{*}{$\begin{array}{c}2.906 \\
* *\end{array}$} & \multirow{3}{*}{3} & \multirow{3}{*}{0.4064} \\
\hline 22 Yrs. & 3 & 10 & 7 & & & \\
\hline \multicolumn{4}{|l|}{ Gender } & & & \\
\hline Female & 4 & 13 & 9 & \multirow{2}{*}{$\begin{array}{c}4.747 \\
* *\end{array}$} & \multirow{2}{*}{3} & \multirow{2}{*}{0.1913} \\
\hline Male & 3 & 3 & 0 & & & \\
\hline $\begin{array}{r}\text { Table } 7 . \\
\text { Demog }\end{array}$ & $\begin{array}{r}\text { Pre-tes } \\
\text { raphic } \\
\mathrm{Nu}\end{array}$ & $\begin{array}{l}\text { st Knowle } \\
\text { Variable } \\
\text { Irsing Sta }\end{array}$ & $\begin{array}{l}\text { dge As } \\
\text { of } \mathrm{Neu} \\
\text { ff. } \mathrm{N}=3\end{array}$ & $\begin{array}{l}\text { sociation } \\
\text { ly Recru } \\
2\end{array}$ & wit & \\
\hline
\end{tabular}

The findings in the above table shows that Chi-square value 2.906 at $\mathrm{df}(3)$ for age $0.4064^{* *}$, Chi-square values 4.747 at df (3) for gender $0.1913^{* *}$ shows no significant association with age, gender and knowledge at 0.05 level of significance. Note- *Significant, ${ }^{* *}$ Not Significant

\begin{tabular}{|c|c|c|c|c|c|c|}
\hline Demographic & Good & Average & Poor & \begin{tabular}{|c|} 
Chi- \\
square
\end{tabular} & Df & $\begin{array}{c}P \\
\text { value }\end{array}$ \\
\hline \multicolumn{7}{|l|}{ Age } \\
\hline 21 Yrs. & 4 & 7 & 0 & \multirow{3}{*}{$\begin{array}{c}3.826 \\
* *\end{array}$} & \multirow{3}{*}{3} & \multirow{3}{*}{0.2809} \\
\hline 22 Yrs. & 11 & 8 & 2 & & & \\
\hline Sex & & & & & & \\
\hline Female & 11 & 14 & 1 & \multirow{2}{*}{$\begin{array}{c}1.258 \\
* *\end{array}$} & \multirow{2}{*}{3} & \multirow{2}{*}{0.7391} \\
\hline Male & 4 & 2 & 0 & & & \\
\hline \multicolumn{7}{|c|}{$\begin{array}{c}\text { Table 8. Post-test Practice Association with } \\
\text { Demographic Variable of newly Recruited } \\
\text { Nursing Staff. } \mathrm{N}=32\end{array}$} \\
\hline
\end{tabular}

Note- *Significant **Not Significant

The findings in the above table shows that Chi-square value 3.826 at $\mathrm{df}(3)$ for age $0.2809^{* *}$, Chi-square value 1.258 at $\mathrm{df}$ (3) for gender $0.7391^{* *}$ shows no significant association with age, gender and practice at 0.05 level of significance.

\section{DISCUSSION}

The present study has been undertaken to assess the effectiveness of planned teaching programme on orientation regarding responsibility of staff nurses among newly appointed Basic B.Sc nurses at Krishna Hospital, Karad.

Similar study conducted by Kapurkar K S on NABH guidelines among newly recruited staff nurses at $\mathrm{K} \mathrm{H}$ Karad study reveals that $90.1 \%$ newly recruited nursing staff belonged to age group of 21 to 23 yrs. and $78.43 \%$ were female. The present study found that majority $(62.5 \%)$ of newly recruited nursing staff belonged to age group of 22 years. Maximum staff (81.25\%) were female, majority $(65.63 \%)$ staff were having $>60 \%$ marks.

Similar study conducted by Makazi Pearl Kunene, "Effectiveness of the Induction and Orientation Programme in the Nkangala Health District of Mpumalanga Province, 2006 to 2007 " reveals that $100 \%$ of the medical doctors and allied health professionals indicated that the induction and orientation programme was effective. ${ }^{2}$

In present study, in pre-test, newly recruited nursing staff were having majority of 50\% average knowledge and 50\% good practice, and in post-test newly recruited nursing staff were having majority of $65.62 \%$ good knowledge and $81.25 \%$ having good practice. It reveals that planned orientation teaching programme regarding responsibility of staff nurses is effective.

Present study reveals that there was significant difference between pre-test and post-test knowledge and practice of newly recruited staff nurses towards orientation programme, $t=5.633$ with thirty-one degree of freedom $p$ value is $<0.0001$.

Present study shows that knowledge score of newly recruited nursing staff between the pre-test and post-test was highly significant as the $\mathrm{p}$ value is $<0.0001$ and practice score of newly recruited nursing staff between the pre-test and posttest was highly significant as the $\mathrm{p}$ value is $<0.0044$.

The findings in the above table shows that Chi-square value 2.906 at $\mathrm{df}(3)$ for age $0.4064^{* *}$, Chi-square value 4.747 at $\mathrm{df}(3)$ for gender $0.1913^{* *}$ shows no significant association with age, gender and knowledge at 0.05 level of significance and Chi-square value 3.826 at $\mathrm{df}(3)$ for age $0.2809^{* *}$, Chisquare value 1.258 at $\mathrm{df}(3)$ for gender $0.7391^{* *}$ shows no significant association with age, gender and practice at 0.05 level of significance.

\section{Future Scope}

\section{Nursing Implication}

The findings of this study have implications for nursing practice, nursing education, nursing administration and nursing research.

\section{Nursing Practice}

The knowledge and practice of orientation programme and standard guidelines needs to be provided to all nursing personnel and can be continued in the hospital.

\section{Nursing Administration}

The finding of the study will help the nurse administrator to organise more workshops, panel discussion, short-term refresher courses and health education programme for nurses. 


\section{Nursing Research}

Research suggests that orientation programme of hospital is a good way to provide standardisation in treatment.

\section{REFERENCES}

1. Marcum EH. West RD. Structured orientation for new graduates: a retention strategy. Journal for Nurses in Staff Dev 2004;20(3):118-26.

2. Makazi Pearl Kurene \& Oq. Research. The Effectiveness of the induction and orientation programme in Nkangala health district of Mpumalanga: https://www.google.co.in/search:(2010).

3. Cuddy JB. Development of an evidence-based nursing orientation programme for a community health system. 2015.

http://scholarworks.waldenu.edu/cgi/viewcontent.cgi?a rticle $=1747 \&$ context $=$ dissertation.

4. Spooner-Lane R, Patton W. Determinants of burnout among public hospital nurses. Australian Journal of Advanced Nursing 2007;25(1):8-16. www.ajan.com.au/vol25/vol25.1-PDF(2007)

5. The Johns Hopkins University. The Johns Hopkins Hospital and Johns Hopkins Health system.

vhttp://www.hopkinsmedicine.org/howard_county_gen eral_hospital/about/careers/education_scholarship_opp ortunities/new_graduate_nurse.html
6. Eisenhart V. What are the benefits of new employee orientation programs? 2011.

Http://smallbusiness.chron.com/benefits-newemployee-orientation-programs-1281.html

7. Ross H, Clifford K. Research as a catalyst for change: the transition from student to registered nurse. Journal of Clinical Nursing 2002;11(4):545-53.

8. Casey K, Fink R. Casey-fink graduate nurse experience survey: survey reliability and validity.//www.uchealth.org/professionals/Pages/Casey -Fink-Survey-Instruments/Casey-Fink-Graduate-NurseExperience-Survey.aspx. (2014).

9. Charleston R, Hayman-White $K$, Ryan $M R$, et al. Understanding the importance of effective orientation: What does this mean in psychiatric graduate nurse programs? Australian Journal of Advanced Nursing 2007;25(1):24-30.

10. Ward CW. Enhancing orientation and retention: one unit's success story. Journal of Continuing Education in Nursing 2009;40(2):87-90.

11. Bashford CW, Shaffer BJ, Young CM. Assessment of clinical judgment in nursing orientation: time well invested. Journal for Nurses in Staff Development 2012;28(2):62-5.

12. Godinez G, Schweiger J, Gruver J, et al. Role transition from graduate to staff nurse: a qualitative analysis. J Nurses Staff Dev 1999;15(3):97-110. 